\title{
JNNP
}

\section{Premature mortality in refractory partial epilepsy: does surgical treatment make a difference?}

G S Bell, S Sinha, J de Tisi, et al.

J Neurol Neurosurg Psychiatry published online May 16, 2010

doi: 10.1136/jnnp.2008.170837

Updated information and services can be found at:

http://jnnp.bmj.com/content/early/2010/05/16/jnnp.2008.170837.full.html

These include:

References This article cites 21 articles, 5 of which can be accessed free at:

http://jnnp.bmj.com/content/early/2010/05/16/jnnp.2008.170837.full.html\#ref-list-1

$\mathbf{P}<\mathbf{P} \quad$ Published online May 16, 2010 in advance of the print journal.

Email alerting Receive free email alerts when new articles cite this article. Sign up in the service box at the top right corner of the online article.

\section{Notes}

Advance online articles have been peer reviewed and accepted for publication but have not yet appeared in the paper journal (edited, typeset versions may be posted when available prior to final publication). Advance online articles are citable and establish publication priority; they are indexed by PubMed from initial publication. Citations to Advance online articles must include the digital object identifier (DOIs) and date of initial publication.

To order reprints of this article go to:

http:/jnnnp.bmj.com/cgi/reprintform

To subscribe to Journal of Neurology, Neurosurgery \& Psychiatry go to:

http://jnnp.bmj.com/subscriptions 


\title{
Premature mortality in refractory partial epilepsy: does surgical treatment make a difference?
}

\author{
G S Bell, ${ }^{1}$ S Sinha, ${ }^{1} \mathrm{~J}$ de Tisi, ${ }^{1}$ C Stephani, ${ }^{2}$ C A Scott, ${ }^{1}$ W F Harkness, ${ }^{1}$ \\ A W McEvoy, J L Peacock, ${ }^{3}$ M C Walker, ${ }^{1}$ S J Smith, ${ }^{1}$ J S Duncan, ${ }^{1}$ \\ J W Sander ${ }^{1,4}$
}

'Department of Clinical \& Experimental Epilepsy, UCL Institute of Neurology and National Hospital for Neurology and Neurosurgery, UCL Hospitals NHS Foundation Trust, London, UK

${ }^{2}$ Department of Clinical Neurophysiology, University of Göttingen, Göttingen, Germany ${ }^{3}$ University of Southampton School of Medicine, Southampton General Hospital, Southampton, UK

${ }^{4}$ SEIN, Epilepsy Institutes in the Netherlands Foundation, Heemstede, The Netherlands

\section{Correspondence to}

Professor Ley Sander, Box 29,

Department of Clinical \& Experimental Epilepsy, UCL Institute of Neurology, Queen Square, London WC1N 3BG, UK; Isander@ion.ucl.ac.uk

Received 18 December 2008 Revised 11 August 2009 Accepted 17 August 2009

\begin{abstract}
Background Epilepsy carries an increased risk of premature death. For some people with intractable focal epilepsy, surgery offers hope for a seizure-free life. The authors aimed to see whether epilepsy surgery influenced mortality in people with intractable epilepsy. Methods The authors audited survival status in two cohorts (those who had surgery and those who had presurgical assessment but did not have surgery).

Results There were 40 known deaths in the non-surgical group (3365 person years of follow-up) and 19 in the surgical group (3905 person-years of follow-up). Nonoperated patients were 2.4 times $(95 \% \mathrm{Cl} 1.4$ to 4.2 ) as likely to die as those who had surgery. They were 4.5 times (95\% Cl 1.9 to 10.9$)$ as likely to die a probable epilepsy-related death. In the surgical group, those with ongoing seizures 1 year after surgery were 4.0 (95\% Cl 1.2 to 13.7) times as likely to die as those who were seizure-free or who had only simple partial seizures. Time-dependent Cox analysis showed that the yearly outcome group did not significantly affect mortality (HR $1.3,95 \% \mathrm{Cl} 0.9$ to 1.8 ).

Conclusion Successful epilepsy surgery was associated with a reduced risk of premature mortality, compared with those with refractory focal epilepsy who did not have surgical treatment. To some extent, the reduced mortality is likely to be conferred by inducing freedom from seizures. It is not certain whether better survival is attributable only to surgery, as treatment decisions were not randomised, and there may be inherent differences between the groups.
\end{abstract}

\section{INTRODUCTION}

Some patients with intractable focal seizures are candidates for surgical treatment, which may be curative. We assessed the survival of patients who had surgery at the National Hospital for Neurology and Neurosurgery (NHNN) and of patients who were evaluated for epilepsy surgery but in whom surgery was not performed.

\section{METHODS}

Surgical cohort

A prospective epilepsy surgery register has been kept at NHNN since 1989 for continuing audit. At annual follow-up, the seizure outcome group for the previous 12 months is recorded using the ILAE epilepsy surgery outcome scale. ${ }^{1}$ Patients in group 1 are completely seizure-free, and those in group 2 may have 'auras.' Groups 3-6 have increasingly more seizures. In the analyses we considered those in groups 1 and 2 as 'seizure-free,' to enable comparison with other published cohorts. The duration of follow-up was estimated from the date of surgery and the date of death, or the date last known to be alive.

\section{Non-surgical cohort}

A register is also kept of patients evaluated for epilepsy surgery. Those who did not have surgery included those deemed unsuitable after investigations, those who declined, those who died before surgery and those who were still awaiting surgery. Individual follow-up was obtained. The duration of follow-up was calculated from the time of initial presurgical evaluation until the date of death, or the date at which each patient was known to be alive.

\section{ANALYSIS}

Person-years of follow-up were estimated for the two groups. The age and duration of follow-up were compared using the Kruskal-Wallis test. Age at time of surgery or investigation (non-operated group) was divided into five groups ( $<25$ years, $\mathrm{N}=221 ; \quad 25-29$ years, $\quad \mathrm{N}=251$ : $30-34$ years, $\mathrm{N}=225$; $35-41$ years, $\mathrm{N}=255$; $\geq 42$ years, $\mathrm{N}=249$ ). Age was unknown for one patient.

Those who had surgery were divided into groups based on seizure outcome group at the first year after surgery and when last seen (outcome group 1 or 2, outcome group 3-6). Patients were further grouped according to whether they remained seizure-free (outcome group 1 or 2) or not seizurefree (outcome group 3-6) throughout follow-up, or whether they moved between these two groups.

Cox regression analysis was performed comparing total mortality, epilepsy-related death and sudden unexplained death in epilepsy (SUDEP) in those who had surgery with those who did not, and comparing mortality in those seizure-free (group 1 or 2) with those not seizure-free at first year after surgery and at last contact. The strength of relationship was estimated by HRs and 95\% CIs; a 95\% CI which excludes 1.00 indicates a statistically significant result

Cox regression was performed to compare those with variable outcome (varying between seizurefree and not seizure-free) and those with seizures throughout follow-up with those seizure-free (group 1 and 2) throughout follow-up. A Coxmodel with time-dependent covariates (with an interaction term between year and outcome class) was used to assess the influence of seizure recurrence on mortality.

Analysis was performed in Stata MP/10 
This audit was approved by the Joint Ethics Committee of NHNN and the Institute of Neurology.

\section{RESULTS}

\section{Patients}

The non-surgical patients were slightly older than the surgical patients and had a shorter median length of follow-up (table 1).

Those with surgery were aged between 16 and 64 years. The maximum follow-up was 17.4 years. In 30 people, follow-up was less than 0.8 years; six died (two of SUDEP, one of cancer, one from a non-epilepsy-related accident, one of suicide and one of infection). An additional 16 people have no outcome groups. In 46 patients, we have only one outcome group; two died, both of cancer.

The pattern of outcome groups and deaths for the remaining patients is shown in table 2 .

The non-surgical group were aged 15-71 years. Twenty-five patients (3.9\%) had no recorded follow-up (some live overseas) and are excluded from the analysis. The maximum follow-up duration is 15.4 years. Of the 40 (6.2\%) known deaths, 20 died of SUDEP, two of possible SUDEP, one drowned, one died in status, one committed suicide, three died of cancer, five died of other unrelated conditions, and in seven the cause of death was unknown to us.

We classified those dying of SUDEP, drowning and status as having probable epilepsy-related deaths $(\mathrm{N}=24$ for the nonsurgical group and 7 for the surgical group).

\section{Survival in the non-surgical and surgical patients}

Those who did not have surgery were more than twice as likely to die during follow-up (HR 2.5; 95\% CI 1.5 to 4.4). Neither gender nor age affected the analysis (HR adjusted for age group and gender $2.4,95 \%$ CI 1.4 to 4.2 ). Age group did not affect outcome independently, although gender affected the outcome on a time-dependent basis.

Those in the non-surgical group were more likely to die from a probable epilepsy-related death than those in the surgical group (HR 4.6; 95\% CI 1.9 to 11.0); this was unaffected by gender or age group (adjusted HR 4.5, 95\% CI 1.9 to 10.9). For SUDEP and possible SUDEP, HR=4.1 (95\% CI 1.7 to 9.9).

\section{Survival by seizure outcome class in surgical patients}

Patients with a follow-up of less than 0.8 years (including six who died) and those with unknown outcome are excluded from the subsequent analyses which are dependent on the seizure outcome group. At the end of the first year, 369 were in outcome group 1 or 2 (four deaths), and 146 were in outcome group 3-6 (nine deaths); those in outcome group 3-6 were 4.8 (95\% CI 1.5 to 15.9 ) times as likely to die as those in group 1 or 2 . This was affected only slightly by gender or age group at surgery (adjusted HR 4.0, 95\% CI 1.2 to 13.7). At last review, 365 were in outcome group 1 or 2 (six deaths) and 150 in group 3-6 (seven deaths).

Table 1 Patient demographics

\begin{tabular}{|c|c|c|c|}
\hline & Non-surgical & Surgical & p Value \\
\hline $\mathrm{N}$ (males) & 641 (309) & $561(262)$ & \\
\hline $\begin{array}{l}\text { Median (IQR) age at operation or } \\
\text { assessment in years }\end{array}$ & 33.4 (27.3 to 41.2$)$ & $31.9(26.4$ to 39.0$)$ & 0.02 \\
\hline Median (IQR) follow-up in years & $5.0(2.6$ to 8.4$)$ & 6.8 (3.1 to 10.7$)$ & 0.0001 \\
\hline Total follow-up (years) & 3365 & 3905 & \\
\hline Deaths & 40 (1 in 84 years) & 19 (1 in 206 years) & \\
\hline Epilepsy-related deaths & 24 ( 1 in 140 years) & 7 (1 in 558 years) & \\
\hline
\end{tabular}

Table 2 Causes of death in patients according to common patterns of outcome

\begin{tabular}{|c|c|c|c|}
\hline Pattern & $\mathbf{N}$ & Deaths & Cause of death \\
\hline Constant outcome: seizure-free & 209 & 2 & Cancer (2) \\
\hline $\begin{array}{l}\text { Constant outcome: never seizure- } \\
\text { free }\end{array}$ & 61 & 4 & Cardiac failure, SUDEP (3) \\
\hline Initially seizure-free, then seizures & 44 & 1 & Cancer \\
\hline Initially seizures, then seizure-free & 58 & 3 & $\begin{array}{l}\text { Cardiac problems, unknown, } \\
\text { SUDEP }\end{array}$ \\
\hline $\begin{array}{l}\text { Initially and finally seizure-free, } \\
\text { with seizures intervening }\end{array}$ & 34 & 0 & \\
\hline $\begin{array}{l}\text { Complex pattern: never seizure- } \\
\text { free }\end{array}$ & 21 & 1 & SUDEP \\
\hline $\begin{array}{l}\text { Complex pattern, including } \\
\text { seizure freedom }\end{array}$ & 42 & 0 & \\
\hline Total & 469 & 11 & \\
\hline
\end{tabular}

In the fifth group (initially and finally seizure-free, with seizures intervening) the transient seizures were frequently caused by stopping AEDs, or by another temporary precipitant. Seizure-free: outcome group 1 or 2; seizures: outcome groups 3-6. SUDEP, sudden unexplained death in epilepsy.

Those in outcome group 3-6 were 2.3 (95\% CI 0.8 to 6.9) times as likely to die as those in group 1 or 2 .

Throughout follow-up, 287 remained in group 1 or 2 (three deaths), 94 remained in group 3-6 (six deaths) and 134 moved between those two groups (four deaths); those consistently in group 3-6 were 4.9 (95\% CI 1.2 to 20.3 ) times as likely to die as those remaining in group 1 or 2 . The HR became non-significant after adjustment for age-group and gender (adjusted HR 4.0 (95\% CI 0.97 to 16.6$)$ ).

The time-dependent Cox analysis showed a weak relationship between yearly outcome group and mortality which did not reach statistical significance (HR 1.29, 95\% CI 0.93 to 1.8). The interaction term was not significant $(p=0.8)$, showing no evidence that the mortality risk varied with time.

No analysis was performed within the surgical group for epilepsy-related deaths, as only five such deaths occurred in people with seizure outcome data (table 2).

\section{DISCUSSION}

We found that those with refractory focal epilepsy who had surgery had a lower risk of premature death than those who did not. Short-term follow-up of epilepsy surgery generally shows a beneficial effect. ${ }^{2-5}$ Seizure status is not always constant over time, ${ }^{34}$ 6-12 and this may affect mortality.

In a randomised controlled trial, 80 patients with temporal lobe epilepsy were randomised to surgical or medical treatment for 1 year; the only death was SUDEP in a medically treated patient. ${ }^{13}$ Another study matched 201 surgical patients with 185 retrospective controls and found no difference in survival, even in a subgroup of 38 patients with controls who could have been surgical candidates. ${ }^{14}$ In common with other studies, we found that those who did not have surgery had shorter survival times than those who $\operatorname{did}^{15} 16$

Our results are similar to a study in surgical patients which reported three deaths in 148 patients who were seizure-free (Engel class I) throughout follow-up and eight deaths in 67 patients not seizure-free. ${ }^{17}$ Another study reported one death in 258 patients with no recurrences and 18 deaths in 325 people with recurrences. ${ }^{18}$

Those with a poor outcome at 1 year were more likely to die than those with good outcome. The outcome group at last follow-up, however, seemed less likely to predict death. No analysis was performed using three groups (non-surgical, surgical with good outcome and surgical with poor outcome), as 
six deaths in the surgical group would be discounted (as death occurred before an outcome group was defined) leading to bias. Time-dependent analysis showed that the relationship between outcome group and mortality was weak, with no evidence at all that this varied with time. The lack of significance of the last outcome group and of the time-dependent analysis may be related to the small number of deaths (13). Despite a long follow-up, the power is limited by the small numbers of deaths and hence large HRs.

One limitation is the difference in follow-up between the groups. Cox regression, however, makes allowance for incomplete follow-up, with those who are 'lost' being followed up to the time at which they were last known to be alive.

Many epilepsy-related causes of death are more common in people with higher seizure frequencies, ${ }^{19}$ and surgery is frequently successful in abolishing seizures. Some of the difference in mortality between those suitable for surgery and those not, and between those who have good seizure outcome and those who do not, however, may be due to intrinsic differences in the patients and their epilepsies, rather than the effects of surgery. $^{20} 21$

Funding This work was carried out at University College London Hospitals/University College London, which received a proportion of funding from the Department of Health's National Institute for Health Research Biomedical Research Centres funding scheme. The study was partly supported by the UK National Society for Epilepsy. SS was supported by a Commonwealth Fellowship. JWS is supported by the Dr Marvin Weil Epilepsy Research Fund.

Competing interests None.

Ethics approval Ethics approval was provided by the Joint Ethics Committee of Institute of Neurology and National Hospital for Neurology.

Provenance and peer review Not commissioned; externally peer reviewed.

\section{REFERENCES}

1. Wieser HG, Blume WT, Fish D, et al. ILAE Commission Report. Proposal for a new classification of outcome with respect to epileptic seizures following epilepsy surgery. Epilepsia 2001;42:282-6.
2. Armon C, Radtke RA, Friedman $\mathrm{AH}$, et al. Predictors of outcome of epilepsy surgery: multivariate analysis with validation. Epilepsia 1996;37:814-21.

3. Elwes RD, Dunn G, Binnie CD, et al. Outcome following resective surgery for temporal lobe epilepsy: a prospective follow up study of 102 consecutive cases. J Neurol Neurosurg Psychiatry 1991:54:949-52.

4. Salanova V, Markand O, Worth R. Longitudinal follow-up in 145 patients with medically refractory temporal lobe epilepsy treated surgically between 1984 and 1995. Epilepsia 1999;40:1417-23.

5. Tanriverdi T, Poulin N, Olivier A. Life 12 years after temporal lobe epilepsy surgery: A long-term, prospective clinical study. Seizure 2008;17:339-49.

6. Cohen-Gadol AA, Wilhelmi BG, Collignon F, et al. Long-term outcome of epilepsy surgery among 399 patients with nonlesional seizure foci including mesial temporal lobe sclerosis. J Neurosurg 2006;104:513-24.

7. Jeong SW, Lee SK, Hong KS, et al. Prognostic factors for the surgery for mesial temporal lobe epilepsy: Iongitudinal analysis. Epilepsia 2005:46:1273-9.

8. Kelemen A, Barsi P, Eross L, et al. Long-term outcome after temporal lobe surgery-prediction of late worsening of seizure control. Seizure 2006;15:49-55.

9. Paglioli E, Palmini A, Paglioli E, et al. Survival analysis of the surgical outcome of temporal lobe epilepsy due to hippocampal sclerosis. Epilepsia 2004;45:1383-91.

10. Spencer SS, Berg AT, Vickrey BG, et al. Predicting long-term seizure outcome after resective epilepsy surgery: the multicenter study. Neurology 2005;65:912-18.

11. Sperling MR, Nei M, Zangaladze A, et al. Prognosis after late relapse following epilepsy surgery. Epilepsy Res 2008;78:77-81.

12. Mclntosh AM, Kalnins RM, Mitchell LA, et al. Temporal lobectomy: long-term seizure outcome, late recurrence and risks for seizure recurrence. Brain 2004;127:2018-30.

13. Wiebe S, Blume WT, Girvin JP, et al. A randomized, controlled trial of surgery for temporal-lobe epilepsy. N.Engl.J.Med 2001;345:311-18.

14. Guldvog B, Loyning Y, Hauglie-Hanssen E, et al. Surgical versus medical treatment for epilepsy. I. Outcome related to survival, seizures, and neurologic deficit. Epilepsia 1991:32:375-88.

15. Nilsson L, Ahlbom A, Farahmand BY, et al. Mortality in a population-based cohort of epilepsy surgery patients. Epilepsia 2003;44:575-81.

16. Vickrey BG. Mortality in a consecutive cohort of 248 adolescents and adults who underwent diagnostic evaluation for epilepsy surgery. Epilepsia 1997;38(Suppl 11): S67-9.

17. Salanova V, Markand 0, Worth R. Temporal lobe epilepsy surgery: outcome, complications, and late mortality rate in 215 patients. Epilepsia 2002:43:170-4

18. Sperling MR, Harris A, Nei M, et al. Mortality after epilepsy surgery. Epilepsia 2005; $\mathbf{4 6}$ (Suppl 11):49-53.

19. Sander JW, Bell GS. Reducing mortality: an important aim of epilepsy management J Neurol Neurosurg Psychiatry 2004;75:349-51.

20. Ryvlin P, Kahane P. Does epilepsy surgery lower the mortality of drug-resistant epilepsy? Epilepsy Res 2003;56:105-20.

21. Persson $\mathbf{H}$, Kumlien E, Ericson $\mathrm{M}$, et al. No apparent effect of surgery for temporal lobe epilepsy on heart rate variability. Epilepsy Res 2006;70:127-32. 